\title{
Structural Contribution of Cold In-Place Recycling Base Layer
}

\author{
Mateo E. Carvajal ${ }^{1}$, Murugaiyah Piratheepan ${ }^{2}$, Peter E. Sebaaly ${ }^{2, *}$, Elie Y. Hajj ${ }^{2}$ and Adam J. Hand ${ }^{2}$ \\ 1 Applied Research Associates, Inc., Gainesville, FL 32609, USA; mateocarvaya17@out-look.com \\ 2 Department of Civil \& Environmental Engineering, University of Nevada, Reno, NV 89557, USA; \\ mpiratheepan@unr.edu (M.P.); elieh@unr.edu (E.Y.H.); adamhand@unr.edu (A.J.H.) \\ * Correspondence: psebaaly@unr.edu
}

check for

updates

Citation: Carvajal, M.E.; Piratheepan, M.; Sebaaly, P.E.; Hajj, E.Y.; Hand, A.J. Structural Contribution of Cold InPlace Recycling Base Layer. CivilEng 2021, 2, 736-746. https://doi.org/ 10.3390/civileng2030040

Academic Editors: Luis Picado-

Santos, José Neves and Mohammad Saberian Boroujeni

Received: 20 July 2021

Accepted: 1 September 2021

Published: 3 September 2021

Publisher's Note: MDPI stays neutral with regard to jurisdictional claims in published maps and institutional affiliations.

Copyright: (C) 2021 by the authors. Licensee MDPI, Basel, Switzerland. This article is an open access article distributed under the terms and conditions of the Creative Commons Attribution (CC BY) license (https:// creativecommons.org/licenses/by/ $4.0 /)$.

\begin{abstract}
Cold in-place recycling (CIR) of asphalt pavements is a process that has successfully been used for many years. The use of CIR for rehabilitation offers many advantages over traditional overlays due to its excellent resistance to reflective cracking and its environmentally friendly impacts. Despite the good performance and positive sustainability aspects of CIR, the structural contribution of the CIR base layer has not been well defined. In this research, CIR mixtures were designed with different asphalt emulsions. The mixtures were then subjected to dynamic modulus, repeated load triaxial, and flexural beam fatigue testing over a range of temperature and loading conditions. The performance test data generated were then used to develop CIR rutting and fatigue performance models used in the mechanistic analysis of flexible pavements. The technique used to develop the performance models leveraged the fact that the rutting and fatigue models for individual CIR mixtures were all within the 95 percent confidence interval of each other. A mechanistic analysis was conducted using the 3D-Move Mechanistic Analysis model. With the laboratory-developed performance models, the structural layer coefficient for the CIR base layer were developed for use in the 1993 AASHTO Guide for the Design of Pavement Structures. This analysis led to the determination of an average structural coefficient of the CIR base layer of 0.25 .
\end{abstract}

Keywords: cold in-place recycling; performance testing; CIR performance models; structural layer coefficient; 1993 AASHTO Guide

\section{Introduction}

Cold in-place recycling (CIR) of asphalt pavements is a process that has successfully been used for many years [1]. CIR is a major pavement rehabilitation treatment, consisting of milling the top 50-75 mm of the asphalt concrete (AC) layer followed by in-place cold mixing with asphalt emulsion and stabilizing agents (i.e., Portland cement or hydrated lime), and compacted using traditional methods [2]. With a more recent focus on sustainability and availability of new emulsions and recycling techniques, CIR continues to be an important pavement rehabilitation tool. However, despite good CIR performance, some engineering properties of this material have not been fully developed.

Traditional rehabilitation techniques for flexible pavements include overlays and mill/overlay. Both of these techniques suffer from the reflection of cracks that exist in the old pavement which limit their service life. In the case of CIR, the high flexibility of the CIR mix offers excellent resistance to reflective cracking while maintaining good resistance to rutting. Other advantages of CIR include the conservation of energy and resources since heating and hauling are not required, therefore energy consumption and greenhouse gas emissions are significantly reduced [3]. On-site recycling is maximized so off-haul and disposal of old materials is reduced. When used as a base layer, the structural capacity of CIR is considerably better than that of an unbound material. CIR is a relatively quick rehabilitation process with machine production rates increasing. It is a long-term cost-effective treatment with reduced maintenance costs.

There are also some disadvantages of using CIR; it requires an overlay or surface treatment as a wearing course. CIR needs to be constructed in relatively warm and dry 
weather, therefore limiting the construction season. CIR without stabilizing agents may be susceptible to moisture damage. In-place density during construction is very challenging to measure and low density can negatively impact performance [4]. When excess Portland cement has been used, CIR has exhibited shrinkage cracking resulting in reflective cracking.

\section{Objective}

The objective of this study was to evaluate the structural contribution of the CIR base layer in the flexible pavement structure. The structural contribution was assessed in the form of the structural layer coefficient for the CIR base layer to be used in the 1993 AASHTO Guide for Design of Pavement Structures [5]. This objective was achieved through mechanistic analyses of flexible pavement structures incorporating engineering properties and performance characteristics of multiple CIR mixtures. The novelty of the research documented in this paper is the development of a structural coefficient for the CIR layer that is based on fundamental mechanistic analyses of flexible pavements. This contribution allows the CIR layer to be incorporated into the structural design process as specified in the 1993 AASHTO Guide, which is widely used throughout the world.

\section{Literature Review}

The increased use of CIR as a rehabilitation technique has generated interest in properly characterizing the behavior of this material. Investigations have been focused in three areas: (1) mix design, (2) engineering and performance properties of CIR mixtures, and (3) performance of CIR pavements. A review of relevant literature focused on the structural behavior of CIR and, particularly, efforts assessing the cracking behavior of CIR follows.

Morian et al. evaluated the performance of 13 CIR projects in Pennsylvania with service lives of up to 20 years [6]. The effectiveness of CIR to resist reflective cracking from underlying concrete pavements was evaluated. The research showed that CIR provided two to three times the resistance to reflective cracking compared with conventionally resurfaced control sections. In addition, CIR demonstrated to be a stress-sensitive material, providing increased stiffness in response to increased load. This behavior was indicated to be an important factor in delaying the development of reflective cracking.

Lin et al. investigated the dynamic characteristics of CIR mixtures using engineered asphalt emulsion (CRME) and cement [7]. Dynamic modulus and phase angle were studied at different curing times. Creep and relaxation tests were performed to determine service conditions at higher temperatures. Fatigue life was evaluated using flexural beam fatigue tests. Cracking characteristics were also evaluated by analyzing fracture interface microstructure with scanning electron microscopy (SEM). The results of this study indicated that CRME is a viscoelastic material based on evidence of time-temperature dependence effects during early and fully cured conditions. According to the Burger model, this material had excellent ability to resist permanent deformation at $60{ }^{\circ} \mathrm{C}$. However, fatigue life of CRME was only $10-20 \%$ of ordinary asphalt mixture at high strain, still meeting the requirements for heavy traffic in China's road structure specifications ( $>25,000,000$ cycle/track).

Gao et al. evaluated the laboratory fatigue behavior of CIR mixtures with digital image correlation (DIC) techniques [8]. The semicircular bending (SCB) test and indirect tensile test (IDT) were utilized to compare the resistance of CIR and hot mix asphalt (HMA) mixtures to crack propagation in the stress-controlled mode of loading. The results indicated that the addition of 1.5 percent Portland cement to CIR mixtures improved overall fatigue performance life. Under the same stress level, the difference between the two regression lines of fatigue for CIR and AC mixtures was not significant. The SCB test showed that initial stiffness of HMA mixtures was about 1.8 times that of CIR mixtures.

An experimental study of fatigue properties of CIR mixtures manufactured with asphalt emulsion and foamed asphalt was conducted by Yan et al. [9]. The Nottingham Asphalt Tester (NAT) was used to evaluate the fatigue behavior. Fatigue life was analyzed at $15{ }^{\circ} \mathrm{C}$ and four stress levels. The results indicated that foam CIR mixtures displayed greater fatigue life at low stress levels, while emulsion CIR mixtures displayed a greater 
fatigue life at high stress levels. Qualitative analysis indicated that emulsion CIR mixtures showed plastic fatigue failure due to viscoelastic characteristics, while fatigue damage of foam CIR mixtures showed brittle fracture. The law of vertical displacement and crack development indicated that emulsion CIR mixtures included three states of displacement development before cracking, while foam CIR mixtures included two stages of displacement development before cracking.

The influence of Portland cement on fatigue life of CIR mixtures treated with pozzolanic materials indicating that, given the crystalline nature of pozzolanic bonds, cemented materials tend to be brittle which can reduce flexibility and fatigue life of CIR mixtures, has been reported [10]. IDT and resilient modulus tests were performed at different temperatures $\left(10\right.$ to $25^{\circ} \mathrm{C}$ ) and curing times (7 to 120 days). Test results showed the effect of cement depends on the initial strain level in the test. At 300 microstrain and above, the addition of cement caused a reduction in fatigue life, while below 300 microstrain the opposite trend was observed.

An assessment of fracture parameters to predict field cracking performance of CIR mixtures was conducted on projects in multiple states [11]. The ability of fracture parameters to predict field cracking performance of CIR pavements was determined based on the performance of nine projects located in three states. The projects consisted of 2-5 year old CIR pavements surfaced with AC overlays. Field pavement performance was assessed based on longitudinal and transverse cracking. Fracture energy was found to be appropriate to differentiate between satisfactory and poor performance. Recommendations included using fracture energy in specifications to optimize the cracking resistance of CIR mixtures.

In addition to laboratory evaluations, several studies have focused on determining the effectiveness of CIR as a reflective cracking control technique. The evaluation of long-term performance of several CIR pavements constructed in Nevada in 1997-1998 was made [12]. The research concluded that CIR is an effective rehabilitation technique for roads with low and medium volume traffic levels. The results proved that CIR produces a more flexible and stable base course than unbound material, with a greater tendency to reduce the development of reflective and thermal cracking as well as rutting.

Schwartz et al. evaluated procedures for determining material properties of coldrecycled asphalt mixtures for input to structural design and analysis [13]. Pavement performance as predicted by Pavement ME Design found that well-designed cold recycled materials gave performances comparable to HMA for high traffic volume pavements with appropriate adjustments. Structural analyses conducted with material properties measured as inputs in Pavement ME Design showed sensitivity of the test data to the different stabilizing agents used.

In 2020, Bowers et al. conducted a survey of state highway agency specifications for pavement recycling, including CIR [14]. The survey identified the following practices: (a) the majority of specifications allow a maximum size of $38 \mathrm{~mm}$ with one or two sieves required, (b) density is the most common construction quality indicator, (c) moisture content and curing time are commonly used to identify time for opening to traffic and time to overlay, respectively, and (d) most specifications listed a minimum temperature for the CIR mix at the time of placement.

The most recent research work on CIR mixtures was conducted under the National Cooperative Highway Research Program (NCHRP) Project 09-62 [15]. This research identified practical test methods that can be used to evaluate the properties of CIR mixtures during construction. The research developed two tests; the short-pin and long-pin tests. The short-pin test was recommended to determine the length of time required prior to opening of the CIR surface to traffic. The long-pin test was recommended to determine the length of time required prior to placing the asphalt concrete overlay over the CIR layer. 
As a follow-up to the NCHRP research, Hand et al. evaluated the ruggedness and developed precision estimates for the short- and long-pin tests [16]. The research concluded that tight tolerances are necessary on pin length and diameter, as well as on pin dullness. The precision estimates recommended a range of accepted results from multi-laboratories, from $7.3 \%$ for the number of blows for the long-pin tests to $35-39 \%$ for the torque from the long-pin test and the number of blows and torque from the short-pin test.

As can be seen from the review of literature, the majority of the research activities are concentrated around evaluations of the properties of CIR mixtures and the performance of CIR pavements. Hence, there is a gap in the current state of knowledge about CIR mixtures, where the engineering properties of the CIR mixtures can be evaluated but the structural value of the CIR layer cannot be determined. The research presented in this paper attempts to fill the gap by developing a structural coefficient for the CIR layer that can be used in the structural design of flexible pavements.

\section{Materials and Evaluations}

\subsection{Materials}

Raw materials used in this research included reclaimed asphalt pavement (RAP), asphalt emulsions, and lime. A single source of RAP was used with the only gradation specification imposed being a maximum size of $25 \mathrm{~mm}$. Four types of asphalt emulsions were used as described in Table 1, in order to determine the impact of asphalt emulsion type on the behavior of CIR mixtures and to expand the applicability of the research findings. In addition, the two levels of lime slurry (LS) used were $4.5 \%$ and $6.0 \%$. The $4.5 \%$ LS consists of $1.5 \%$ hydrated lime and $3.0 \%$ water, while the $6.0 \%$ LS consists of $2.0 \%$ hydrated lime and $4.0 \%$ water. A total of eight CIR mixtures were evaluated in this research; four asphalt emulsions and two levels of lime slurry.

Table 1. Properties of Asphalt Emulsions.

\begin{tabular}{cccc}
\hline Asphalt Emulsion & $\begin{array}{c}\text { Asphalt } \\
\text { Residue (\%) }\end{array}$ & $\begin{array}{c}\text { Modifier Type and } \\
\text { Content (\%) }\end{array}$ & $\begin{array}{c}\text { Superpave PG of } \\
\text { Asphalt Residue }\end{array}$ \\
\hline Type A: CMS-2S & 65 & None & PG52-34 \\
\hline Type B: Latex-Modified & 72 & Latex (3\%) & PG64-28 \\
\hline Type C: Polymer-Modified & 76 & SBS * $(\%)$ & PG64-28 \\
\hline Type D: Rubber-Modified & 65 & Tire Rubber $(10 \%)$ & PG58-28 \\
\hline * Styrene-Butadiene-Styrene. & &
\end{tabular}

\subsection{Mix Designs}

CIR mix designs were performed using the Superpave mix design method [17]. Previous CIR mix design work for the Nevada Department of Transportation (DOT) led to unique procedures for mixing time, curing time, theoretical maximum specific gravity determination $\left(\mathrm{G}_{\mathrm{mm}}\right)$ and optimum emulsion content (OEC) determination [18]. The Superpave mix designs for the eight CIR mixtures were developed by Ayala [18]. The OEC determined for the various CIR mixtures are presented in Figure 1. Note that all percentages are expressed in terms of a percent of the dry weight of RAP. The OEC's were selected at compacted mixture air voids of $13 \pm 1 \%$. For the performance tests, compacted samples were subjected to conditioning at $60^{\circ} \mathrm{C}$ for $48 \mathrm{~h}$ prior to coring and/or cutting for testing size. All performance test specimens were compacted to $13 \pm 1 \%$ air voids. 


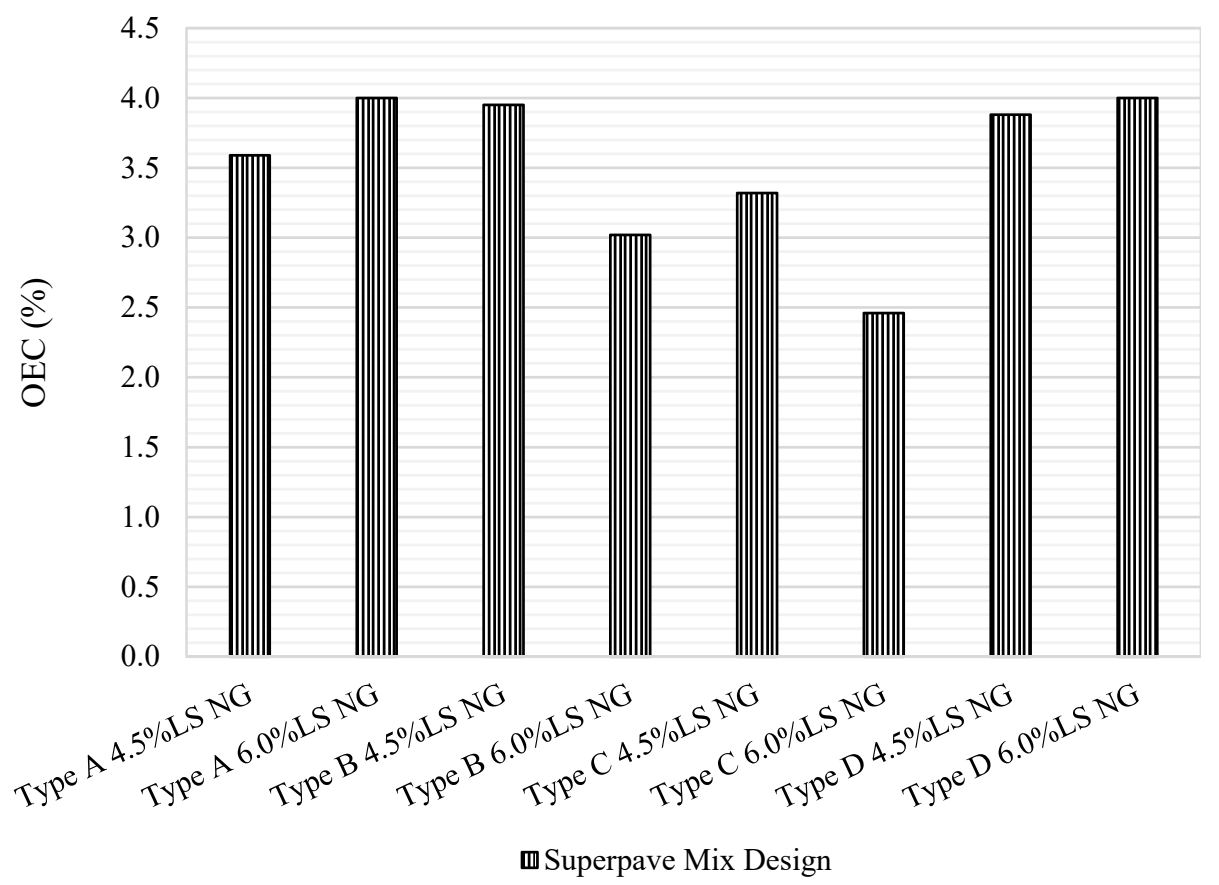

Figure 1. Optimum emulsion content based on Superpave mix design.

\subsection{Engineering Property}

Dynamic modulus $\left(E^{*}\right)$ represents the engineering property of an asphalt mixture, which relates the applied stress to the resulted strain. It is measured by applying sinusoidal axial load and measuring the associated sinusoidal axial strain at a given temperature and frequency of load application. Due to the viscoelastic nature of CIR mixtures, the $\mathrm{E}^{*}$ is determined at different temperatures and loading frequencies. The measured $\mathrm{E}^{*}$ values are used to develop a master curve which can be used to estimate the property at any combination of temperature and loading frequency. Dynamic modulus tests were performed in accordance with AASHTO T378 and the master curves were built following AASHTO R84 [19].

The dynamic modulus master curves for the eight CIR mixtures were measured and reported by Ayala [18]. The statistical analyses of the master curves indicated that all eight CIR mixtures can be represented by a single master curve which is capable of representing any of the eight CIR mixtures within the $95 \%$ confidence interval (CI) [18]. The single $\mathrm{E}^{*}$ master curve in $\mathrm{MPa}$ is presented in Equation (1).

$$
\log \left(\mathrm{E}^{*}\right)=1.29172+\frac{2.75409}{1+e^{\left(-1.446248-0.376021 \log f_{r}\right)}}
$$

\subsection{Fatigue Characteristics}

The resistance of the CIR mixtures to fatigue cracking was evaluated using the flexural beam fatigue test as per ASTM D7460 [20]. In this test, the beam specimens are subjected to a four-point bending with free rotation and horizontal translation at all load and reaction points. This produces a constant bending moment over the center portion of the specimen. In this research, constant strain tests were conducted at multiple strain levels between 250 and 800 microstrain, using a repeated haversine load at a frequency of $10 \mathrm{~Hz}$, and three test temperatures of $12.8^{\circ} \mathrm{C}, 21.1^{\circ} \mathrm{C}$ and $29.4^{\circ} \mathrm{C}$. 
The fatigue characteristics for the eight CIR mixtures were measured and reported by Carvayal [20]. The statistical analyses of the fatigue performance models indicated that all eight CIR mixtures can be represented by a single fatigue model which is capable of representing any of the eight CIR mixtures within the 95\% CI [20]. The single fatigue model is presented in Equation (2).

$$
N_{f}=4.38 * 10^{2} *\left(\frac{1}{\varepsilon}\right)^{4.243} *\left(\frac{1}{E^{*}}\right)^{3.440}
$$

where:

$$
\begin{aligned}
& N_{f}=\text { number of cycles to failure; } \\
& \varepsilon=\text { tensile strain, } \mathrm{mm} / \mathrm{mm} \text {; and } \\
& E^{*}=\text { dynamic modulus, } \mathrm{MPa} \text {. }
\end{aligned}
$$

\subsection{Rutting Characteristics}

The repeated load triaxial (RLT) test was used to evaluate the rutting characteristics of the CIR mixtures. The permanent $\left(\varepsilon_{p}\right)$ and resilient $\left(\varepsilon_{r}\right)$ axial strains were measured during the RLT test as a function of the number of load repetitions at three different temperatures; $20{ }^{\circ} \mathrm{C}, 36.5^{\circ} \mathrm{C}$, and $53{ }^{\circ} \mathrm{C}$ [18]. RLT samples with $100 \mathrm{~mm}$ diameter by $150 \mathrm{~mm}$ height with $13 \pm 1 \%$ air voids were cored from samples compacted in the Superpave Gyratory compactor to dimensions of $150 \mathrm{~mm}$ diameter by $175 \mathrm{~mm}$ height. The RLT testing was performed by applying a deviator stress $\left(\sigma_{d}\right)$ of $275 \mathrm{kPa}$ and a confinement stress $\left(\sigma_{c}\right)$ of $173 \mathrm{kPa}$ by placing a rubber membrane around the test specimens. The specimens were subjected to 12,000 cycles of $0.1 \mathrm{~s}$ of haversine load, followed by $0.9 \mathrm{~s}$ of rest period. Vertical deformations were measured at the center $100 \mathrm{~mm}$ portion of the specimens using two LVDTs spaced $180^{\circ}$ apart.

The rutting characteristics for the eight CIR mixtures were measured and reported by Ayala [19]. The statistical analyses of the rutting performance models indicated that all eight CIR mixtures can be represented by a single rutting model which is capable of representing any of the eight CIR mixtures within the 95\% CI [18]. The single rutting model is presented in Equation (3).

$$
\frac{\varepsilon_{p}}{\varepsilon_{r}}=10^{-3.4486} *(N)^{0.2788} *(T)^{2.0237}
$$

where:

$$
\begin{aligned}
& \varepsilon_{P}=\text { Permanent strain, } \mathrm{mm} / \mathrm{mm} ; \\
& \varepsilon_{r}=\text { Resilient strain, } \mathrm{mm} / \mathrm{mm} ; \\
& N=\text { Number of load repetitions; and } \\
& T=\text { Temperature, }{ }^{\circ} \mathrm{C} .
\end{aligned}
$$

\section{Mechanistic Analysis of CIR Pavements}

A mechanistic analysis of the CIR pavement was performed by incorporating the measured engineering properties in terms of dynamic modulus, along with performance characteristics in terms of fatigue and rutting of the evaluated CIR mixtures, into the analysis approach illustrated in Figure 2. 
Inputs for Mechanistic Analysis

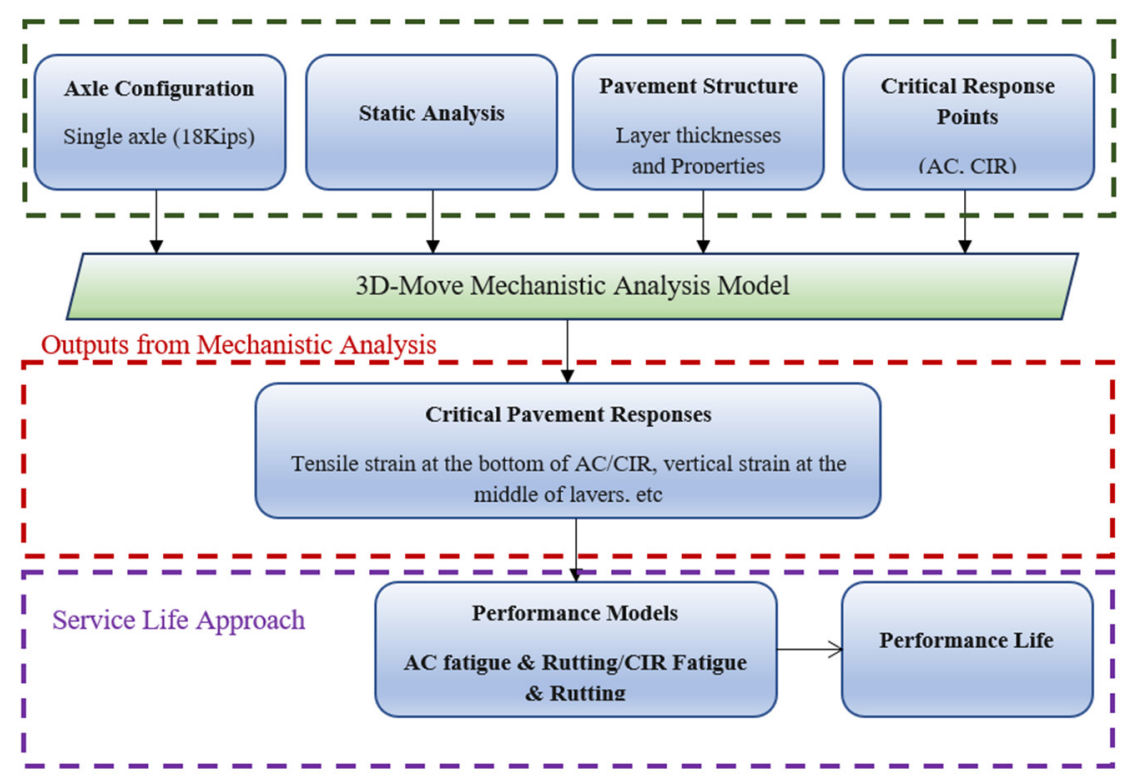

Figure 2. Flow chart of mechanistic analysis approach.

The determination of the structural layer coefficient for the CIR base layer to be used in the 1993 AASHTO Pavement Design Guide followed the approach listed below:

1. Establish a flexible pavement structure with $75 \mathrm{~mm} \mathrm{CIR}$ base layer and $50 \mathrm{~mm}$ new AC overlay as shown in Figure 3.

2. Determine the critical strains for fatigue and rutting performance of the CIR pavement. Use the critical strains to estimate the fatigue and rutting lives of the CIR pavement through the models presented in Equations (2) and (3), respectively.

3. Determine the required thickness of the new AC layer in the AC pavement underneath the $50 \mathrm{~mm}$ new AC overlay, as shown in Figure 3, to match the fatigue and rutting performance lives for both the CIR and AC pavements.

4. Determine the total structural number (SN) of the equivalent $\mathrm{AC}$ pavement, as determined in step 3, using the known structural coefficients of the various layers in the AC pavement.

5. Assume that the CIR pavement provides the same $\mathrm{SN}$ as the equivalent $\mathrm{AC}$ pavement to determine the structural coefficient of the CIR base layer-defined as the product of the ratio of the thickness of AC layer over the thickness of CIR layer times the known structural coefficient of the AC layer.

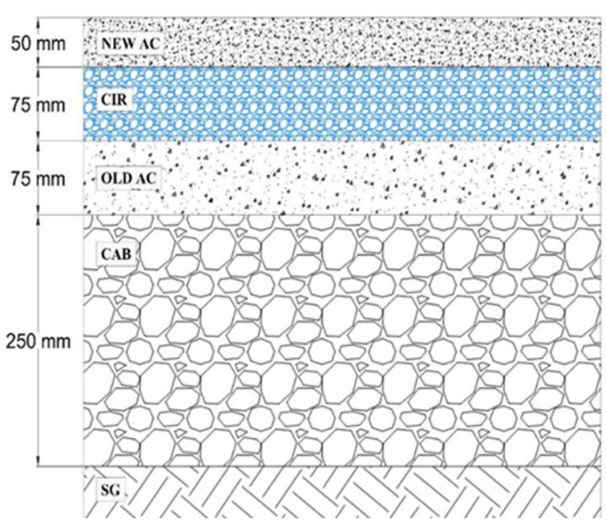

CIR Pavement

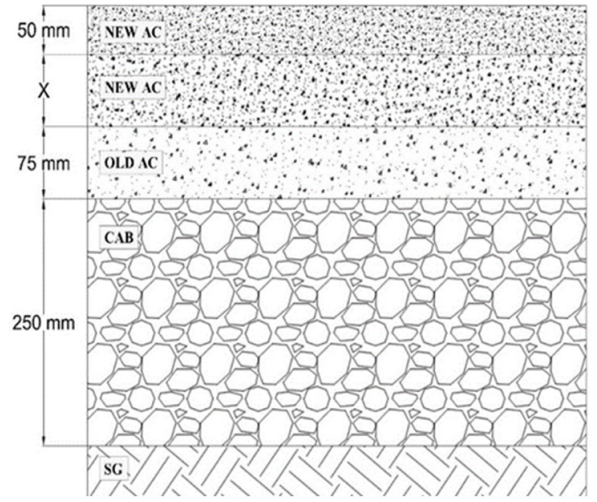

AC Pavement

Figure 3. Flexible pavement structures using CIR and AC layers. 


\subsection{Calculation of Pavement Responses}

The 3D-Move pavement analysis software was used to determine the pavement responses due to applied load [21]. The 3D-Move model is based on a finite-layer approach and uses the Fourier transform technique to evaluate the responses of the layered medium subjected to a moving load traveling along the $\mathrm{x}$-axis at a constant speed. The properties of the AC layer can be either linear elastic (i.e., for static analyses such as those conducted in this study) or viscoelastic (i.e., for dynamic analyses). The properties of the unbound layers are linear elastic. Material properties are assumed to be uniform and constant within the layer. The 3D-Move model can handle any number of layers with complex loading at the surface and any number of response evaluation points.

For the purpose of this research, the pavement structure was subjected to the load induced by a single axle with dual tires spaced at $355 \mathrm{~mm}$ and a uniform circular load of $20 \mathrm{kN}$ each. The response points were selected under the center of the tire load, the edge of the load, and the center of the dual tires; at the bottom for fatigue and at the middle for rutting of each asphalt bound layer (i.e., CIR and AC).

\subsection{Estimation of Equivalent Pavement Structures}

The five steps approach described earlier was used to calculate equivalent pavement structures for fatigue performance based on using the fatigue performance models and the tensile strain at the critical locations (bottom of CIR or AC layer). For rutting performance, the approach was based upon using the rutting performance models and a fixed number of cycles to reach an equivalent rut depth in both pavement structures. The Nevada DOT specifies $4.0 \mathrm{~mm}$ as the total maximum allowed rut depth in the AC layers.

The following assumptions were made for the analysis. The temperature of CIR was assumed constant and equal to the AC layer temperature at $50 \mathrm{~mm}$ below the pavement surface. For the pavement structure rehabilitated with new AC layer and AC overlay, the temperature at $25 \mathrm{~mm}$ was selected for the top $50 \mathrm{~mm}$ of the AC layer, and the temperature at $50 \mathrm{~mm}$ was selected for the remaining depth of the AC layer. Performance models of the new AC layers were obtained from Nevada DOT's ME-Design database [22]. Dynamic modulus of the existing AC layer was calculated through Equation (4), using the same master curve assumed for the new $\mathrm{AC}$ at corresponding frequency and temperature with a damage value of $d_{a c}=0.6$.

$$
E_{\text {dam }}^{*}=10^{\delta}+\frac{E_{\text {Undam }}^{*}-10^{\delta}}{1+e^{-0.3+5 * \log d_{A C}}}
$$

where:

$\delta=$ minimum dynamic modulus obtained from fitting the master curve, $\mathrm{MPa}$;

$E_{\text {Undam }}^{*}=$ undamaged dynamic modulus, $\mathrm{MPa}$; and

$d_{A C}=$ damage value, assumed 0.6.

With the properties of each layer, the tensile strains were calculated at the bottom of the CIR layer. The number of cycles to fatigue failure was calculated with the average fatigue performance model presented in Equation (2). The tensile strain required to reach that number of cycles was determined with the respective performance fatigue models for typical AC mixtures in northern and southern Nevada. The final step was determining the required thickness of the new $\mathrm{AC}$ layer to match the strain value calculated at the bottom of the CIR layer.

In the case of the rutting analysis, the resilient strains at the middle of each layer were calculated. Using the resilient strain, maximum rut depth, thickness, analysis temperature, and the performance model of each layer, the numbers of cycles $(\mathrm{N})$ to reach the selected rut depth of $4.0 \mathrm{~mm}$ were calculated for the CIR pavement. Finally, the required thickness of the new AC layer to achieve the same rut depth (i.e., $4.0 \mathrm{~mm}$ ) under the same number of load cycles was determined. 


\subsection{Calculation of CIR Structural Layer Coefficient Based on Fatigue Performance}

The final step of the process was to determine the structural layer coefficient for the CIR layer controlled by fatigue performance. Based on the equivalent structure methodology described earlier, it was assumed that the pavement rehabilitated with CIR and the reconstructed pavement with new AC layer have the same SN. The coefficient of the CIR layer was calculated by equating the SN's of the two pavement structures along with the known coefficients of all other layers in the pavement. Equation (5) was used to determine the structural number of the entire pavement structure.

$$
S N=\sum_{i}^{n-1} D_{i} * a_{i}
$$

where:

$D_{i}=$ thickness of interest layer

$a_{i}=$ layer coefficient of interest layer

$n=$ number of layers excluding the SG

\subsubsection{Northern Nevada Pavement Structure}

The mechanistic analysis indicated that the tensile strain at the bottom of the CIR layer structure with a PG64-28NV AC overlay was 199 microstrain. This level of microstrain leads to 7,368,742 cycles to failure when used in the CIR fatigue model in Equation (2). The tensile strain required to reach the same number of cycles to failure for a typical mixture in northern Nevada (PG64-28NV) was found to be 201 microstrain. The results indicated that the $75 \mathrm{~mm}$ CIR layer is equivalent to $57 \mathrm{~mm}$ of the standard AC layer with a PG64-28NV asphalt binder. The fatigue-based layer coefficient was calculated as the ratio of new AC layer thickness $(57 \mathrm{~mm})$ over the thickness of the CIR layer $(75 \mathrm{~mm})$ times the structural coefficient of the new AC layer (0.35); $(57 \mathrm{~mm} / 75 \mathrm{~mm}) \times 0.35=0.27$.

\subsubsection{Southern Nevada Pavement Structure}

The mechanistic analysis indicated that the tensile strain at the bottom of the CIR layer structure with a PG76-22NV layer was 198 microstrain. This level of microstrain leads to 22,043,998 cycles to failure when used in the CIR fatigue model presented in Equation (2). The tensile strain required to reach the same number of cycles to failure for a typical mixture in southern Nevada (PG76-22NV) was found to be 187 microstrain. The mechanistic analysis indicated that the $75 \mathrm{~mm}$ of CIR layer is equivalent to $50 \mathrm{~mm}$ of standard AC overlay manufactured with a PG76-22NV asphalt binder. The fatigue-based layer coefficient was calculated as the ratio of new AC layer thickness $(50 \mathrm{~mm})$ over the thickness of the CIR layer $(75 \mathrm{~mm})$ times the structural coefficient of the new AC layer (0.35); $(50 \mathrm{~mm} / 75 \mathrm{~mm}) \times 0.35=0.23$.

\subsection{Calculation of CIR Structural Layer Coefficient Based on Rutting Performance}

Based on the RLT test results and the average rutting model presented in Equation (3), a full mechanistic analysis was conducted for the CIR mixtures. The procedure and assumptions used to study rutting performance were similar to those used to evaluate the fatigue performance. The main difference was that the approach used to determine equivalent pavement structures for rutting performance is based upon using the rutting performance models and a fixed number of cycles to reach an equivalent rut depth in both pavement structures. In this case, the $4.0 \mathrm{~mm}$ maximum allowed rut depth in the AC layers specified by the Nevada DOT was used as the failure criterion.

For the purpose of this study, the resilient strains at the middle of each layer were calculated. Using the resilient strain, maximum rut depth, thickness, analysis temperature, and the performance model of each layer, the number of cycles $(\mathrm{N})$ to reach the selected rut depth of $4.0 \mathrm{~mm}$ were calculated for the CIR pavement. Then, the required thickness of the new AC layer to achieve the same rut depth (i.e., $4.0 \mathrm{~mm}$ ) under the same number of load 
cycles was determined. This analysis used the properties of typical northern (PG64-28NV) and southern (PG76-22NV) Nevada sections.

\subsubsection{Northern Nevada Pavement Structure}

The mechanistic analysis indicated that the $75 \mathrm{~mm}$ CIR layer is equivalent to $215 \mathrm{~mm}$ of the standard AC layer with a PG64-28NV asphalt binder. The rutting-based layer coefficient was calculated as the ratio of new AC layer thickness $(215 \mathrm{~mm})$ over the thickness of the CIR layer $(75 \mathrm{~mm}$ ) times the structural coefficient of the new AC layer (0.35); $(215 \mathrm{~mm} / 75 \mathrm{~mm}) \times 0.35=1.00$.

\subsubsection{Southern Nevada Pavement Structure}

The mechanistic analysis indicated that the $75 \mathrm{~mm}$ CIR layer is equivalent to $165 \mathrm{~mm}$ of the standard AC layer with a PG76-22NV asphalt binder. The rutting-based layer coefficient was calculated as the ratio of new AC layer thickness $(165 \mathrm{~mm})$ over the thickness of the CIR layer $(75 \mathrm{~mm})$ times the structural coefficient of the new AC layer (0.35); $(165 \mathrm{~mm} / 75 \mathrm{~mm}) \times 0.35=0.77$.

\section{Conclusions}

The objective of this study was to evaluate the structural contribution of the CIR layer within typical Nevada flexible pavements. Eight different combinations of CIR mixtures were assessed, with four emulsion types and two levels of lime slurry. Results of dynamic modulus, flexural beam fatigue, and repeated load triaxial tests were successfully used to assess the behavior of CIR mixtures in a mechanistic analysis based on models developed from the test results. The following conclusions are made based on the data and analyses presented in this paper:

i The type of emulsion and level of lime slurry did not have a significant impact on the $\mathrm{E}^{*}$ master curves, rutting performance, and fatigue performance of the eight CIR mixtures evaluated, making it possible to develop average performance models for each property with $95 \%$ of confidence intervals covering the range of performance observed.

ii The fatigue-based mechanistic analysis conducted revealed a range of structural layer coefficients for CIR from 0.23 to 0.27 , with an average structural layer coefficient of 0.25 being recommended for CIR mixtures.

iii The rutting-based mechanistic analysis conducted revealed a range of structural layer coefficients for CIR from 0.77 to 1.00 , indication that the CIR rehabilitation technique presents a significant improvement in the overall rutting performance of pavements.

iv The mechanistic analyses showed that fatigue cracking is the more critical distress mode for CIR pavements. Therefore, the fatigue-based structural coefficient of the CIR base layer of 0.25 is recommended for use in the design of flexible pavements following the 1993 AASHTO Design Guide.

$\mathrm{v}$ It is recommended that future research efforts should focus on the calibration of the laboratory-developed rutting and fatigue performance models using actual field data, in order to be used in the mechanistic-empirical design method for CIR pavements.

Author Contributions: Conceptualization, P.E.S.; methodology, E.Y.H.; validation, M.P.; formal analysis, M.E.C.; investigation, M.E.C.; resources, P.E.S.; data curation, M.P.; writing-original draft preparation, M.E.C.; writing-review and editing, A.J.H.; supervision, P.E.S. All authors have read and agreed to the published version of the manuscript.

Funding: This research was funded by the Nevada Department of Transportation, Grant \#P643-15-803.

Data Availability Statement: Not applicable.

Conflicts of Interest: The authors declare no conflict of interest. 


\section{References}

1. Jahren, C.T.; Cawley, B.; Bergeson, K. Performance of Cold In-Place Recycled Asphalt Cement Concrete Roads. J. Perform. Constr. Facil. 1999, 13, 128-133. [CrossRef]

2. Asphalt Recycling and Reclaiming Association, 2nd ed.; Basic Asphalt Recycling Manual: Annapolis, MD, USA, 2015.

3. Thenoux, G.; Gonzalez, A.; Dowling, R. Energy consumption comparison for different asphalt pavements rehabilitation techniques used in Chile. Resour. Conserv. Recycl. 2007, 49, 325-339. [CrossRef]

4. Sebaaly, P.E.; Ortiz, J.A.; Hand, A.J.; Hajj, E.Y. Practical method for in-place density measurement of cold in-place recycling mixtures. Constr. Build. Mater. 2019, 227, 116731. [CrossRef]

5. American Association of Highway and Transportation Officials (AASHTO). 1993 Guide for Design of Pavement Structures; American Association of State Highway and Transportation Officials: Washington, DC, USA, 1993.

6. Morian, D.A.; Oswalt, J.; Deodhar, A. Experience with Cold In-Place Recycling as a Reflective Crack Control Technique: Twenty Years Later. Transp. Res. Rec. J. Transp. Res. Board 2004, 1869, 47-55. [CrossRef]

7. Lin, J.; Hong, J.; Xiao, Y. Dynamic characteristics of $100 \%$ cold recycled asphalt mixture using asphalt emulsion and cement. J. Clean. Prod. 2017, 156, 337-344. [CrossRef]

8. Gao, L.; Ni, F.; Ling, C.; Yan, J. Evaluation of fatigue behavior in cold recycled mixture using digital image correlation method. Constr. Build. Mater. 2016, 102, 393-402. [CrossRef]

9. Yan, J.; Ni, F.; Yang, M.; Li, J. An experimental study on fatigue properties of emulsion and foam cold recycled mixes. Constr. Build. Mater. 2010, 24, 2151-2156. [CrossRef]

10. Kavussi, A.; Modarres, A. Laboratory fatigue models for recycled mixes with bitumen emulsion and cement. Constr. Build. Mater. 2010, 24, 1920-1927. [CrossRef]

11. Charmot, S.; Romero, P. Assessment of Fracture Parameters to Predict Field Cracking Performance of Cold In-Place Recycling Mixtures. Transp. Res. Rec. J. Transp. Res. Board 2010, 2155, 34-42. [CrossRef]

12. Sebaaly, P.E.; Bazi, G.; Hitti, E.; Weitzel, D.; Bemanian, S. Performance of Cold In-Place Recycling in Nevada. Transp. Res. Rec. J. Transp. Res. Board 2004, 1896, 162-169. [CrossRef]

13. Schwartz, C.W.; Diefenderfer, B.K.; Bowers, B.F.; National Cooperative Highway Research Program; Transportation Research Board. Material Properties of Cold In-Place Recycled and Full-Depth Reclamation Asphalt Concrete; National Academies Press: Washington, DC, USA, 2017.

14. Bowers, B.F.; Allain, D.E.; Diefenderfer, B.K. Review of Agency Pavement Recycling Construction Specifications. Transp. Res. Rec. J. Transp. Res. Board 2020, 2674. [CrossRef]

15. Diefenderfer, B.K.; Boz, I.; Habbouche, J.; Jones, D.; Hand, A.J.; Bowers, B.F.; Flintsch, G. Proposed AASHTO Practice and Tests for Process Control and Product Acceptance of Asphalt-Tretaed Cold Recycled Pavements; National Cooperative Highway Research Program, Report 960; Transportation Research Board: Washington DC, USA, 2020.

16. Hand, A.J.; Boz, I.; Piratheepan, M.; Hierholzer, F.; Diefenderfer, B.K.; Jones, D.; Habbouche, J.; Louw, S. Ruggedness Evaluation and Precsion Estimates for Newly Developed Test Methods for Asphalt-Treted Cold Recycled Pavements. Transp. Res. Rec. J. Transp. Res. Board 2021, I-II.

17. Piratheepan, M.; Sebaaly, P.E.; Hajj, E.Y.; Selvaratnam, S. Evaluation of Long-Term Performance of Cold In-Place Recycling Pavements in Nevada (Appendices); University of Nevada: Reno, NV, USA, 2014.

18. Ayala, F. Hveem Mix Design and Engineering Properties of Cold In-Place Recycling Mixtures. Master's Thesis, University of Nevada, Reno, NV, USA, 2018.

19. American Association of State Highway and Transportation Officials. Standard Practice for Developing Dynamic Modulus Master Curves for Asphalt Mixtures Using the Asphalt Mixture Performance Tester (AMPT); R84-17; AASHTO: Washington, DC, USA, 2017.

20. Carvayal, M. Evaluation of Cracking Behavior of Cold In-Place Recycling Asphalt Mixtures. Master's Thesis, University of Nevada, Reno, NV, USA, 2018.

21. Siddharthan, R.V.; Hajj, E.Y.; Sebaaly, P.E.; Nitharsan, R. Formulation and Application of 3D-Move: A Dynamic Pavement Analysis Program; Report: FHWA-RD-WRSC-UNR-201506; University of Nevada: Reno, NV, USA, 2015.

22. Hajj, E.Y.; Sebaaly, P.E.; Nabhan, P. Manual for Designing Flexible Pavements in Nevada Using AASHTOWare Pavement-ME Design; University of Nevada: Reno, NV, USA, 2017. 